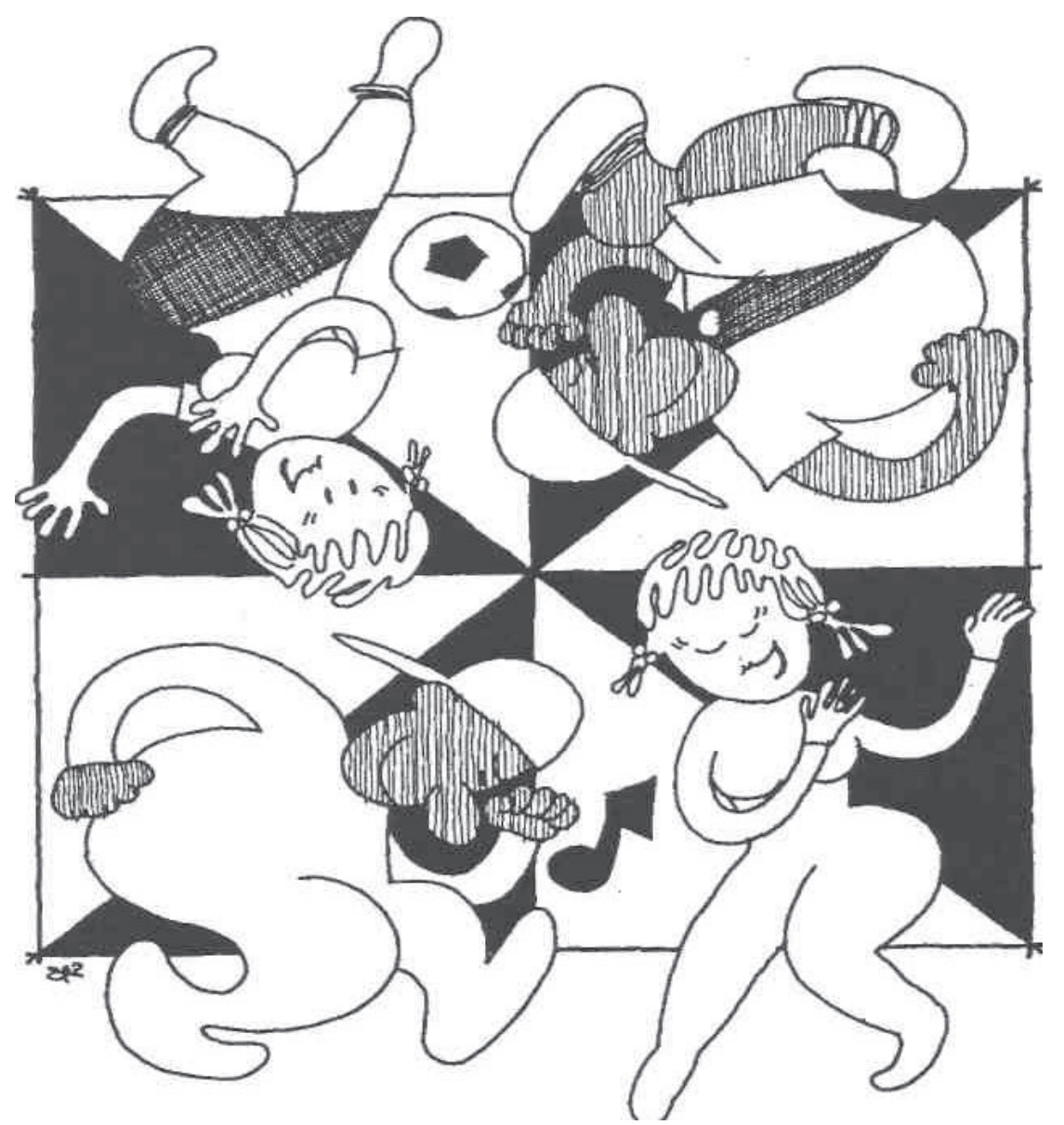

\title{
concepções de gênero
}

\section{nas práticas corporais}

\section{de adolescentes}

... Colecionamos os produtos da indistria humana, recolhemos textos escritos e orais, mas continuamos a ignorar tão mumerosas e variadas possibilidades do corpo do homem - esse instrumental universal e portanto colocado à disposição de todos ... (Lévi-Strauss, 1974).

\section{*Alex Branco Fraga}

Este trabalho toma por base de análise um pequeno recorte das variadas possibilidades do significado do corpo do homem, dando ênfase aos impasses identificatórios que se estabelecem nas relações de sexo-gênero no cotidiano da escola pública Carlos Antônio Wilkens, localizada no município de Cachoeirinha, Rio Grande do Sul, onde alunos adolescentes de $8^{\mathrm{a}}$ série do primeiro grau, com idades que variam entre 13 e 15 anos, explicitam padrões de comportamento e temperamento através de atitudes corporais observadas nas aulas de Educação Física. 
A opção por uma turma com a qual mantivemos vínculo de trabalho por aproximadamente dois anos se deu quando sentimos a necessidade de sistematizar teoricamente uma série de significados, até então dispersos nos atos de cada aluno, a partir de situações áulicas ${ }^{1}$ que envolviam práticas corporais.

A escolha desse objeto impõe aqui uma breve reflexão sobre a questão da observação participante ou da "participação observante", que fundam os limites teóricos deste estudo (Oliven, 1985).

Ruth Cardoso, citando um artigo de Mintz, comenta que a amizade, oriunda de uma relação intersubjetiva, não se interpõe entre pesquisador e pesquisado como um véu que impede a visão da "verdade" ou da "realidade". Pelo contrário, muitas vezes é a convivência e a afetividade entre ambos que permite ao cientista chegar mais perto e mais fundo dos significados que se pretende investigar (Cardoso, 1986).

Gilberto Velho corrobora com esse pensamento dizendo que

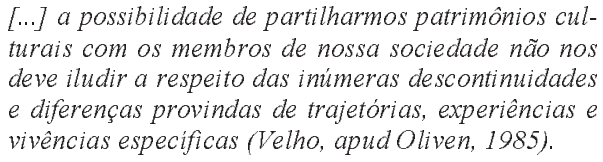

[...] a possibilidade de partilharmos patrimônios culturais com os membros de nossa sociedade não nos deve iludir a respeito das inimeras descontinuidades e diferenças provindas de trajetórias, experiências e vivências especificas (Velho, apud Oliven, 1985).

Podemos afirmar que, neste trabalho, o vínculo que se estabelece nas relações professor-alunos não se funda na amizade pessoal, mas numa outra forma de relação intersubjetiva, isto é, numa comunicação simbólica estruturada na turma, em seu conjunto

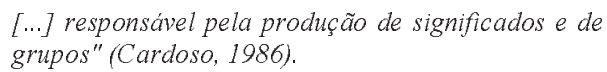

Foram submetidas à análise comparativa as práticas do futebol e da dança, buscando verificar como são incorporados pelos adolescentes valores de referência de sexo-gênero. Sendo assim, temos no futebol o reconhecimento, em nossa cultura, de padrões comportamentais de predominância masculina; porém, ao colocarmos as meninas atuando junto com os meninos nessa atividade, numa mesma equipe, percebemos uma mudança gradual na postura de ambos, havendo uma maior compreensão para com as características de um e de outro.
Por outro lado, na dança preponderam padrões femininos, onde percebemos um processo similar ao do futebol quanto às condutas. Inicialmente, cada grupo escolheu uma modalidade de dança como rock, rap, dance music e tango argentino, que foram apresentados pelos alunos como trabalho de conclusão do ano letivo na I Mostra de $\operatorname{Dança~}^{2}$ da escola. Nesse contexto, foram apreciados de forma mais detalhada a dance music e o tango argentino, por terem sido considerados os mais representativos.

Tanto em uma quanto em outra atividade desenvolvida, utilizamos o critério de distribuição proporcional de meninos e meninas na formação de grupos áulicos para que pudéssemos observar, em atividades corporais distintas, os significados que emanam dessa relação.

\section{QUESTÕES DE GÊNERO NA LÓGICA DRAMÁTICA DOS ADOLESCENTES}

Tratar de gênero em relação a práticas corporais distintas, tendo como referência etária a adolescência, nos remete a uma prudente restrição, isto é, uma delimitação mais clara do assunto em questão, pois

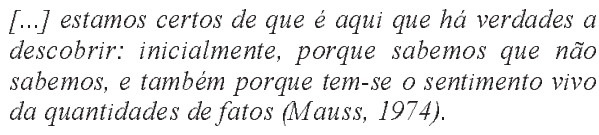

[...] estamos certos de que é aqui que há verdades a descobrir: inicialmente, porque sabemos que não sabemos, e também porque tem-se o sentimento vivo da quantidades de fatos (Mauss, 1974)

\section{Segundo Mauss,}

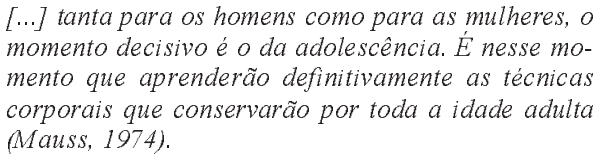

[...] tanta para os homens como para as mulheres, o momento decisivo é o da adolescência. É nesse momento que aprenderão definitivamente as técnicas corporais que conservarão por toda a idade adulta (Mauss, 1974)

A ambigüidade, portanto, é uma marca substancial nessa fase da vida, onde o adolescente já não é mais aquela criança, mas também ainda não é adulto (Rodrigues, 1986).

Por não estar definido com clareza seu papel na sociedade, entra constantemente em conflito, principalmente quando aparecem os primeiros sinais físicos desse período, como o surgimento dos pêlos pubianos, a mudança no timbre da voz e o crescimento da barba ou dos seios, sinais que procuram esconder para que não sejam alvo de anedotas.

Toda a sociedade humana, de alguma 
forma, estabelece uma série de ritos que representam a passagem da adolescência contemporânea. Esse período não está bem definido cronologicamente, podendo variar dentro de uma mesma classe social, criando-se um interstício no sistema de classificação societal, que leva os grupos de adolescentes a reagirem das mais variadas maneiras.

Em algumas culturas, há festejos para uma menina quando menstrua; em outras, esse acontecimento é vergonhoso e precisa ser escondido. Algumas sociedades ignoram a puberdade por completo ou valorizam apenas um dos sexos (Rodrigues, 1986).

Nas sociedades modernas industriais, atribui-se cada vez mais cedo responsabilidade para os adolescentes, como já ocorre em sociedades ditas primitivas. ${ }^{3}$ Nas classes populares, essa "adultização" prematura dos jovens acelera-se, pois estes precisam trabalhar para aumentar a renda familiar ou, se não conseguem, ficam responsáveis pelos irmãos mais novos enquanto os pais estão no emprego.

Nesse sentido, a indumentária reflete bem esse processo. Segundo Winick, a linha divisória entre adolescentes e adultos nesse item começou a desaparecer nos anos 40, cuja "cultura da juventude" começa a se configurar nos trajes e na aparência das gerações (Winick, 1972).

Hoje, não só os meninos e as meninas perderam a noção de que as roupas e a aparência assinalam etapas diferentes de vida, como também os adultos, que, impulsionados pela moda "teen" (termo inglês que se refere à adolescência), buscam no ideal da eterna juventude um lugar de realização, tido cultural e socialmente como de "prestígio".

Nesse particular, cabe ressaltar que no Brasil vem ocorrendo um fenômeno social contemporâneo muito interessante: ao mesmo tempo que se considera a adolescência uma fase ambígua e de difícil compreensão, esta vem recebendo especial atenção dos meios de comunicação, como se pode verificar nos programas de televisão, revistas semanais e suplementos de jornais destinados a essa faixa etária.
Os pormenores dessa presença intensa do adolescente na mídia favorece, também, a uma dinâmica cultural no relacionamento entre os sexos, que ruma à "dessexualização" ${ }^{4}$ na aparência, nos gestos e no modo dos adolescentes se colocarem no mundo. ${ }^{5}$

Fator importante na contribuição dessa mudança de padrões de comportamento pode ser encontrado nos movimentos sociais deflagrados nos anos 60. Nesse sentido, o movimento feminista, tido como precursor da liberação sexual, contribui para a divulgação dos ideais de igualdade de direitos com os homens, e, mais tarde, os movimentos homossexuais vieram contribuir com essas alterações de valores tradicionais.

Não se pode negar que a cultura norteamericana exerce uma considerável influência sobre a sociedade brasileira desde os anos 50 , provocada pela universalização da comunicação de massa e seus padrões de consumo, onde os valores "teens" são prestigiados por uma cultura que privilegia o hedonismo, o sensualismo e o culto ao corpo.

Podemos tomar emprestado o conceito de imitação prestigiosa elaborado por Mauss, que diz:

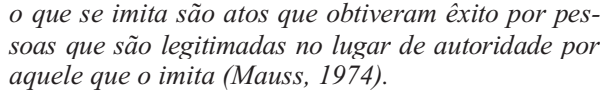

Neste texto pretendemos analisar um grupo de adolescentes em suas relações cotidianas, percebendo-os em suas condutas frente às diferenças de sexo-gênero, a partir de práticas corporais vivificadas na escola.

A hipótese que se segue é de que tais adolescentes vivem, na ambiência escolar, uma situação de despolarização sexual, oriunda de uma rupturização na cadeia simbólica outrora marcada pelo romantismo dos anos 50 , onde buscavam-se características de sexo-gênero recíprocas e complementares. Do ponto de vista da vida escolar, trata-se de se exigir uma re-significação, um novo olhar, sobre as diretrizes em que está sendo construída, na contemporaneidade, a cadeia de valores.

Nesse ponto, conforme Claude LéviStrauss,

\section{A hipótese que se segue é que tais adolescentes vivem, na ambiência escolar, uma situação de despolarização sexual, oriunda de uma rupturização na cadeia simbólica outrora marcada pelo romantismo dos anos 50, onde buscavam-se características de sexo-gênero reciprocas e complementares.}


é próprio da natureza da sociedade exprimir-se simbolicamente em seus costumes e em suas instituições; contrariamente as condutas individuais normais, jamais serão simbólicas por elas mesmas: são elementos a partir dos quais um sistema simbólico, que só pode ser coletivo, se constrói (Lévi-Strauss, 1974).

Portanto, a desterritorialização de valores, a perda da idéia de complementaridade nas relações sociais e o acirramento de um "tribalismo" são marcas do nosso tempo e estão em consonância com uma sociedade que autoriza a produção e o consumo da "cultura da juventude" homogênea, fundada nas fronteiras da imagem liminar dos "teen-agers".

\section{IMPASSES IDENTIFICATÓRIOS NAS PRÁTICAS CORPORAIS DE ADOLESCENTES}

A inovação implementada aqui não reside na formação de um time feminino dentro de um grupo misto, mas sim de colocar meninos e meninas a jogarem juntos, distribuídos de forma proporcional numa mesma equipe.

\section{Futebol: a desconstrução da "casa de homens"}

O futebol adquiriu importância em nossa análise como ponto de referência comparativa à dança, por ser um esporte que ainda mantém uma cadeia simbólica tipicamente masculina.

É um esporte extremamente difundido no nosso país e representa um dos mais fortes traços de identificação cultural da população brasileira (Da Matta, 1982).

Essa modalidade esportiva é praticada pelas diferentes classes sociais e pelas mais variadas idades, mas até bem pouco tempo, era um dos referenciais mais caros à identidade do homem brasileiro, e se tornava redundante colocar o adjetivo masculino à palavra futebol, pois esta trazia em si mesma a própria idéia de homem.

Passam a se desenhar novos territórios na estruturação dos papéis sexuais de ambos nessa prática desportiva, onde os adolescentes são os protagonistas dessa transição.

A inovação implementada aqui não reside na formação de um time feminino dentro de um grupo misto, mas sim de colocar meninos e meninas a jogar juntos, distribuídos de forma proporcional numa mesma equipe.

Para o grupo de meninos investigados, o futebol era como as "casas de homem" dos Tchambuli. ${ }^{6}$ As meninas podem entrar nas práti- cas esportivas onde predomine o futebol somente em certas ocasiões cerimoniais, ocupando seu lugar de poder. Fenômeno semelhante a este ocorreu em nosso país, num dos campeonatos regionais de futebol masculino profissional, onde mulheres atuaram como juízas em algumas partidas oficiais, assumindo um lugar de autoridade similar ao encontrado naquela tribo.

No entanto, o poder preponderantemente masculino reconhecido nesse jogo por seu temperamento agressivo, viril e competitivo passou a diluir-se entre os sexos com o transcorrer das atividades escolares, abrandando tais características nos meninos e salientando-as nas meninas com relativa freqüência.

Isso porque, na arena desafiadoramente masculina, o novo papel da mulher acabou realmente sendo um sinal de que

\section{[...] ela agora partilha um pouco do nível de compe- tição há muito considerado como uma característica masculina (Mead, 1988)}

Nesse sentido, o comportamento do grupo de adolescentes investigados ao longo do trabalho com o futebol nos mostrou que esses movimentos transitórios, observados no cotidiano de uma aula, não são apenas decorrentes dessa fase da vida, mas também se enlaçam no contexto transitório em que vivemos atualmente, onde, como diz Winick,

\section{nenhum dos dois sexos se encerram num padrão de conduta: homens e mulheres ainda sentem a si pró- prios e ao mundo dentro de maneiras que refletem as duas grandes modalidades do paternal e do ma- ternal (Winick, 1988).}

Sem dúvida, estava presente no ambiente áulico um esboço de igualdade entre os sexos,

\section{[...] mas igualdade não significa equivalência, e uma diferença não constitui deficiência, ao contrário, es- tabelece sentido (Winick, 1972),}

desencadeando uma série de outros processos nas mais variadas instâncias da vida escolar.

\section{A dança de papéis}

Tal qual como se processou no jogo de futebol, com a introdução da dança no contexto áulico, observou-se uma mudança significativa nos padrões de comportamentos representados, até então, por práticas corporais desportivas. 
De um lado, os meninos relutavam em participar de algo que consideravam inicialmente ridículo, pois imaginavam que o tipo de dança a ser desenvolvido seria algo semelhante ao ballet, o que para eles significaria a absorção consentida de uma técnica corporal reconhecidamente feminina.

As meninas viam com bom grado a proposta de atividades rítmicas de forma conjunta, pois, pela primeira vez, havia a possibilidade de executar movimentos ligados ao seu universo mais familiar, cabendo aos meninos o processo de adaptação mais significativo

A medida que as aulas aconteciam, a angústia dos rapazes diminuía na mesma proporção em que se sentiam mais identificados com seu papel na dança.

A negação de outrora, por medo da perda da identidade masculina e, por conseguinte, de suas referências, cede lugar a uma boa desenvoltura nos meandros do território alheio, advindas de uma segurança que começava a se construir. ${ }^{7}$

Com relação à prática da dança no conteúdo áulico, optamos aqui em trabalhar $a$ dance music e tango, que marcaram, em sua oposição, comportamentos divergentes tanto nos adolescentes que foram parte integrante do espetáculo quanto naqueles que estavam na platéia.

Para o grupo que optou pela dance music, a tarefa de "estoricizar" os passos tornou-se complicada.

Essa dança é "prima-irmã" das danças pop cultuadas nas discothèques surgidas no início dos anos 70, nos Estados Unidos, marcada por uma batida frenética e constante, sem variações melódicas, onde cada indivíduo, independente do sexo, dança sacudindo o corpo todo no mesmo ritmo, voltados um para o outro, mas raramente estabelecendo uma comunicação, inaugurando um estilo autístico e ensimesmado (Winick, 1972).

No caso da dance music, podemos verificar que o processo de dessexualização, ou seja, de indiferenciação dos valores de sexo-gênero apontados anteriormente, se torna mais explícito: tem-se a impressão mecânica, robotizada dos gestos, os passos são repetitivos e executados da mesma forma por ambos os sexos.
À primeira vista, parece um conjunto harmonioso e integrado, interdependente na sua estrutura interna, porém, à luz da investigação de inúmeros detalhes e pormenores, observa-se a mesma estrutura para os dois sexos (Mauss, 1974).

Assim, ao analisarmos mais atentamente essa dança contemporânea, tipicamente cultuada pelos adolescentes, percebe-se que há uma homogeneização do gesto, onde tudo é paralelo e nada se complementa, pois nunca se tocam, perdendo assim a singularidade diferenciadora.

Esse comportamento passa a ser compreendido quando observamos os ídolos famosos de tais adolescentes, representantes do ideal de totalidade andrógina,

\section{realização em cada um de nós do masculino e feminino ao mesmo tempo (Baudrillard, 1990).}

O exemplo mais emblemático é o do cantor Michael Jackson, que sintetiza o ideal de androginia, ao mesmo tempo masculino/ feminino, como também é o símbolo da complementaridade de opostos: adulto/criança e negro/branco. Um mutante solitário que se transformou, minuciosamente, em andrógino artificial (Baudrillard, 1990).

Portanto, dentro desse contexto, a dance music apresentada por alunos de uma escola municipal em Cachoerinha permeia uma série de valores mundiais que foram incorporados em nossa cultura.

As roupas utilizadas no dia da apresentação nos fornecem mais dados para a análise feita até agora. Os meninos e as meninas usavam bonés, óculos escuros, camisetas comuns (uma das meninas vestia uma camiseta de clube de futebol) e bermudas; somente duas meninas usavam saias, mas que se assemelhavam às bermudas das demais.

A alternativa encontrada por esse grupo para o enredo proposto foi o de começarem dançando sozinhos um menino e uma menina, onde ambos tinham a função de espelho para os outros que iam entrando. Estes, por sua vez, deveriam passar a impressão de pacatos aprendentes que, com seus esforços individuais, se moldariam ao todo igualador.

Nesse sentido, não havia história a ser
O comportamento do grupo de adolescentes investigados ao longo do trabalho com o futebol nos mostrou que estes movimentos transitórios, observados no cotidiano de uma aula, não são apenas decorrentes desta fase da vida, mas também se enlaçam no contexto transitório em que vivemos atualmente. 
$A$ interação entre os pólos masculino e feminino se dava no jogo de sedução; a cada gesto mais agressivo e viril dos meninos, a cada olhar

"caliente" das meninas, num enlaçar de corpos ora resignados, ora desafiadores. contada coletivamente, pois essa dança baseiase numa auto-realização que não se destina à contemplação passiva de uma platéia, é uma

\section{[...]pantomima de movimentos desinteressados e au- tônomos (Winick, 1972)}

onde a lógica se estabelece nos passos simétricos, nos fragmentos perdidos e na participação solitária. Não há tensão entre os sexos porque não há comunicação entre os mesmos.

Contrariamente, no espetáculo baseado no tango, o tema das diferenças de sexo-gênero contrastaram com os dados anteriores, reveladores de uma descontinuidade vital para que o sistema simbólico dos adolescentes seja compreendido.

O trabalho do grupo estruturou-se a partir de um aluno que fazia aulas particulares de tango numa academia de dança da cidade. Esse menino era discretamente marginalizado pelos demais por não manifestar, na maioria das vezes, interesses comuns aos dos meninos de sua idade.

Entretanto, para os "dançarinos" de tango, um estilo de dançar distante dos padrões culturais em que vivem, o ponto de referência estava claro e legitimado nesse aluno que conhecia a dança. Para alguns dos integrantes, a única associação possível era com as danças folclóricas gauchescas, típicas do extremo sul do país, onde podemos encontrar similaridades na representação dos papéis de cada sexo.

Quando começaram os ensaios, havia um certo encantamento por parte dos demais grupos, que fixavam seus olhares assim que os primeiros passos eram executados.

O contraste com o grupo da dance music não se deu somente com o tipo de figurino que acompanhava o tango, mas também com a história que se desenvolvia.

Os meninos vestiam calças de tergal com sapatos e camisas sociais; um deles portava um paletó com um lenço branco no bolso e gel nos cabelos, devidamente penteados. As meninas usavam vestidos longos de cortes diferentes, mas igualmente provocantes; seus cabelos, pomposamente armados; apenas uma delas com os cabelos soltos, e todas de sapatos de salto. Na medida em que os passos se desenrolavam, o conflito gerado pelo ritual de aproximação e afastamento do casal dançarino se estampava na coreografia de gestos e intenções.

A interação entre os pólos masculino e feminino se dava no jogo de sedução: a cada gesto mais agressivo e viril dos meninos; a cada olhar "caliente" das meninas; num enlaçar de corpos ora resignados, ora desafiadores.

A dramática das diferenças de gênero se tornou mais transparente nessa dança, pois, no jogo de sedução peculiar ao tango, os adolescentes aprenderam que

\section{[...] a diferença faz o sentido; a partir daí, as coisas, os comportamentos, os pensamentos e os sentimen- tos se constituem em mensagens significantes (Saussure, apud Rodrigues, 1986).}

A polarização, o reconhecimento da diferença, daquilo que estranha: a sexualidade, o erotismo, o sensualismo magnetizou o grupo de adolescentes envolvido nessa prática corporal, resgatando códigos de valores pertencentes a uma outra época que foram "re-semantizados". ${ }^{8}$

Nesse ponto, tratando-se de memória da dança, convém concordar que

\section{[...] nada mais (nem mesmo Deus) desaparece pelo fim ou pela morte, mas por proliferação... (Baudrillard, 1990).}

Sendo assim, os códigos simbólicos referenciais que embasam qualquer cultura, mesmo que estejam aparentemente enterrados, permanecem como valores inerentes e, de tempos em tempos, emergem no cotidiano, identificando-nos enquanto seres humanos.

\section{CONSIDERACÕES FINAIS}

Para que se possa alcançar uma maior eficácia no ato de observar e refletir tal objeto de análise, torna-se necessário ressaltar alguns tópicos deste estudo.

Primeiramente, em qualquer cultura, nenhuma prática corporal enseja em si mesma as noções substantivas de sexo-gênero, não só porque há transformações a partir de uma dinâmica cultural, dentro de uma mesma sociedade, mas porque tais transformações nos remetem a uma dimensão semântica que está contida no processo de configuração de identidades sociais, mesmo aquelas que se fundam 
em papéis sexuais (Duarte, 1986).

Nesse sentido, torna-se equivocada a análise estática de uma fase da existência humana, como na adolescência, marcada pela ambigüidade e cujo dinamismo exigiria uma amplitude de interpretação de seus gestos, costumes ou hábitos culturais, pois

[...] a sociedade permite agora a prática de uma arte aos membros dos dois sexos, do mesmo modo poderá também permitir o desenvolvimento de muitos dotes temperamentais contrastantes em cada sexo (Mead, 1988)

Eis porque penso ser imprescindível o estudo mais aprofundado das relações de sexogênero na adolescência, exatamente ali onde os atores sociais se estranham, ou seja, no conflito gerado por situações cotidianas de convívio mútuo.

\section{REFERÊNCIAS BIBLIOGRÁFICAS}

BADRILLARD, Jean. A transparência do mal: ensaio sobre os fenômenos extremos. Campinas : Papirus, 1990.

CARDOSO, Ruth C.L. As aventuras de antropólogos em campo ou como escapar das armadilhas do método. In: CARDOSO, Ruth CL. (org.) Aventura antropológica: teoria e pesquisa. Rio de Janeiro : Paz e Terra, 1986.

Da MATTA, Roberto. Esporte na sociedade: um ensaio sobre o futebol brasileiro. In: Universo do futebol: esporte e sociedade brasileira. Rio de Janeiro : Pina Kothecke, 1982.

DUARTE, Luis Fernando D. Da vida nervosa dos trabalhadores urbanos. Rio de Janeiro: Zahar, 1986.

FERREIRA, Aurélio Buarque de Holanda. Novo dicionário da língua portuguesa. $2^{\mathrm{a}}$ ed. Rio de Janeiro : Nova Fronteira, 1986.

LÉVI-STRAUSS, Claude. Introdução à obra de Marcel Mauss. In: MAUSS, Marcel. Sociologia e antropologia. São Paulo : EDUSP, 1974.

MAUSS, Marcel. Sociologia e antropologia. São Paulo : EDUSP, 1974.

MEAD, Margareth. Sexo e temperamento. 3.ed. São Paulo : Perspectiva, 1988.
OLIVEN, Ruben G. A antropologia de grupos urbanos. Petrópolis : Vozes, 1985.

RODRIGUES, José Carlos. Tabu do corpo. $4^{\mathrm{a}} \mathrm{ed}$. Rio de Janeiro : Dois Pontos, 1986.

WINICK, Charles E. Unissexo: a dessexualização da sociedade americana. São Paulo: Perspectiva, 1972.

\section{NOTAS}

1 "Relativo ou referente à aula" (Ferreira, 1986, p. 200).

${ }^{2}$ Esta Mostra foi registrada em vídeo e utilizada como instrumento de análise neste estudo.

${ }^{3} \mathrm{Na}$ sociedade Arapesh, recai sobre o menino, ao chegar à adolescência, o ônus de cultivar inhames, cuidar do sagu e caçar, com o que alimentará a sua pequena futura esposa, que possui, normalmente, entre 7 e 8 anos de idade (Mead, 1988).

${ }^{4}$ Termo usado por Winick para se referir a cres cente mudança nos papéis sexuais rumo à neutrali dade, advinda da despolarização e do deslocamen to da identidade sexual (Winick, 1972).

${ }^{5}$ Os meninos, hoje em dia, usam cabelos compridos e, em algumas ocasiões, usam "tiara" para prendêlos; as meninas, além das calças compridas já incor porada há um bom tempo em seu costume, não se constrangem mais em sentar com as pernas afasta das ou com as mesmas sobre uma outra cadeira.

${ }^{6}$ Um lugar onde os homens podem manter-se iso lados das mulheres e estabelecer seus próprio có digos rituais, isto é, fugir da relação conflitante com o sexo feminino, que detém a posição de poder naquela cultura (Mead, 1988).

${ }^{7}$ De acordo com Mauss, cada sociedade tem hábi tos que lhe são próprios, havendo uma sociedade com instruções de gênero distintas para ambos os sexos (Mauss, 1974). É certo que estes hábitos apre sentam uma referência de tradição, porém, atual mente, pode-se pensar que as técnicas corporais di ferenciais estão sendo apropriadas ora por um, ora por outro sexo, provocando uma despolarização na cadeia de símbolos, diferenciando-se cada vez mais no detalhe.

${ }^{8}$ Sobre este conceito ver: Oliven, Ruben G. Vio lência e cultura no Brasil. Petrópolis: Vozes, 1982.

\section{UNITERMOS}

Corpo - Gênero - Escola

* Alex Branco Fraga é Professor da Rede Municipal de Ensino de Cachoeirinha, RS. 